\title{
Research Paper: Normalization and Validation of a $\odot$ (@) Questionnaire on Effective Life Skills for Prevention, Treatment, and Rehabilitation of Addiction in Adolescents
}

Hossein Gharaati Sotoudeh ${ }^{1}$ (D), Masoud Arefnazari ${ }^{{ }^{*}}$ (iD

1. Department of Psychology, Roudehen Branch, Islamic Azad University, Roudehen, Iran.

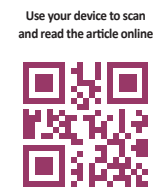

Citation: Gharaati Sotoudeh H, Arefnazari M. Normalization and Validation of a Questionnaire on Effective Life Skills for Prevention, Treatment, and Rehabilitation of Addiction in Adolescents. Iranian Rehabilitation Journal. 2020; 18(2):231-238. http://dx.doi.org/10.32598/irj.18.2.910.2

http://dx.doi.org/10.32598/irj.18.2.910.2

Article info:

Received: 28 Sep 2019

Accepted: 18 Jun 2020

Available Online: 01 Jun 2020

\section{Keywords:}

Life skills test, Adolescents, Questionnaire

\section{A B S T RACT}

Objectives: The purpose of this study was to normalize and validate a questionnaire on effective life skills for prevention, treatment, and rehabilitation of addiction in an adolescent population (age $>10$ years) from Tehran, Iran.

Methods: To prepare the questionnaire, several standard questionnaires were combined, including self-control, problem-solving, decision-making, and assertiveness questionnaires. Afterward, the validity and reliability of the questionnaire were confirmed.

Results: The questionnaire consisted of 40 questions on four main skills including 10 questions targeting one specific skill. The questionnaire was examined among 160 adolescents, aged $\geq 5$ years, in different parts of Tehran, Iran. Cronbach's alpha coefficient was measured to determine its reliability. The reliability of the questionnaire was calculated based on the ratio of internal variances; Cronbach's alpha of all items of the designed questionnaire was above 0.7, indicating its acceptable reliability.

Discussion: The questionnaire on effective life skills for prevention, treatment, and rehabilitation of addiction in adolescents had a completely novel design, which was established for the first time in Iran. According to the findings, it is possible to evaluate the adolescents' skills regarding addiction prevention and treatment. 


\section{Highlights}

- This article assessed life skills as one of the most important factors in the prevention, rehabilitation, and treatment of addiction due to the lack and availability of other tools and questionnaires in adolescence.

\section{Plain Language Summary}

In recent years, many scholars and activists have addressed this issue in an attempt to cure, prevent, or treat addiction; however, whether all interventions in these areas can be effective is an important question. Answering this question requires an indexing tool that precisely measures this point and being able to show us the changes quantitatively.

\section{Introduction}

rug abuse among adolescents and youth is particularly important because of the high sensitivity of this population and its role in the future of individuals. This issue becomes even more important when the prevalence of substance abuse among adolescents and young adults increases during the years of formal education. Therefore, careful attention must be paid to this problem among students, as it can be an effective step for identifying the factors associated with substance abuse and providing effective preventive strategies. Regarding drug use. the period of peak prevalence is $18-25$ years of age [1]. According to the latest Mental Health Survey by the Ministry of Health, the age of onset of tobacco consumption in Iran has reached 12 years of age and with the mean age of onset of 16 years of age [2].

Formerly, the only prevention strategy for drug abuse was limited to the publication of pamphlets that warned youngsters about the dangers of drugs, which mostly resulted in no change or only a minor change in their behavior. However, nowadays science has rendered us able to alter that situation. Using evidence-based strategies for dealing with families, schools, and local communities, it can be assured that children and adolescents, particularly in the indigent and marginalized groups, will healthily and safely grow into adults. The experience in various countries has demonstrated that given the extremely high costs of acting against drug supply and trafficking, addict treatment, and maintenance, substance abuse prevention is highly cost-effective. By devoting every dollar to prevention, at least ten dollars can be saved for the community health and crime prevention [3].

Available evidence suggests that uneducated and illiterate people are at a greater risk of addiction, compared with economically disadvantaged adults. On the one hand, the prevalence of substance abuse in all groups and social classes, especially privileged and educated people, is increasing [4]. According to the pattern of addiction in Iran, the age of onset of drug use is decreasing and also youth and adolescents are at a greater risk of this disorder [4]. According to the latest mental health survey, this rate has reached 12 years, with an average age of 15 years [5]. Also, more than $60 \%$ of crimes are related to drugs, and more than six million people are affected by various drugs.

Every day, eight people die due to drug abuse, and 70 people become addicted. Meanwhile, the number of young addicts is increasing, and the age of drug use onset is decreasing. In a study on adolescents aged 15-18 years, $33 \%$ declared that their drug use was harmless, while they were eight times more likely to use drugs than their peers. Also, 91\% of adolescents do not have the required self-control skills or resistance against peer pressure, therefore; they are more likely to be at risk of addiction [5]. Generally, drug use and abuse are developmental phenomena, which their rates have been increased from adolescence to young adulthood [6]. The peak inclination towards addiction starts from early adolescence into early adulthood [6]. A study by Young [7] revealed a growing and steady increase in the consumption of tobacco, alcohol, and cannabis during adolescence.

The educational system has only considered the students' level of scientific literacy in recent years resulting in the students' inability to apply their scientific knowledge, in addition to their insufficient skills to communicate effectively with society and cope with problems. In addition, it has increased their vulnerability to everyday problems and has caused many mental, emotional, social, and health problems. These individuals are incapable of solving their own problems and are unable to make the right decisions about their personal and social issues.

Today, drug addiction and abuse are the most important concerns of students' families. Adolescents' use of ciga- 
rettes, alcohol, and other illicit drugs is one of the major health, psychological, and social challenges, facing most countries worldwide. There are also numerous personal, social, and health problems, threatening different societies. In most non-pharmacological treatments, which are complementary to pharmacotherapy, the emphasis is on changing the consumers' lifestyle by establishing eight basic life skill training programs for prevention, treatment, and rehabilitation of addiction, as emphasized by the Office of Addiction.

\section{Different theories and viewpoints about life skill training}

Life skill training has recently been considered in Iranian psychology and education. It is known that individual misconduct and social problems result from a combination of environmental, social, and individual factors; however, the final behavior is decided by the individual. Generally, social people need professional life skills. Life skill training refers to making responsible decisions to have a healthy lifestyle. Training started at an early age and tailored to the level of children's and adolescents' skills, can create feelings of competence, efficiency, decision-making ability, purposefulness, and suitable behaviors.

Gazda et al. have described life skills as the required skills and knowledge in four domains of family, education, community, and occupation. This concept is based on a general theory with an emphasis on counseling for increasing mental health so that each of these domains can be defined and quantified objectively [8]. According to the description proposed by Darden et al., fourteen life skills are necessary for an effective lifestyle, which should be considered in all stages of life (childhood, adolescence, and adulthood [9].

Moreover, Gilchrist and Maxwell in 1991 (Bavadi quoting in 2002) reported that life skills include the development of adolescents' self-sufficiency and problemsolving ability with a friendly and direct approach to create and maintain social support and control personal emotions. Khakpour also considers life skills as a person's psychosocial abilities for adaptive and effective behaviors, which enable him/her to effectively deal with problems of everyday life. Training of these skills can promote personal and social growth, protect human rights, and prevent psychosocial problems.

Life skills include effective interpersonal relationships, social responsibility, and suitable decision-making for resolving conflicts, without resorting to actions, which can harm the person or others [10]. Numerous studies have shown that life skills are effective in the following domains:

Improvement of mental and physical health: strengthening self-esteem and self-confidence; equipping individuals with effective ways of coping with environmental and psychological stress; helping young people to develop friendships; and promoting healthy social behaviors.

Prevention of psychological problems and antisocial behaviors: smoking and drug abuse; stress and depression; physical abuse at school; suicidal tendencies and thoughts; and academic failure.

Therefore, life skill training is a new approach, which requires a new outlook [10].

Goals of life skill training program:

\section{Mental health promotion and primary prevention of social injuries}

The main purpose of life skill training programs is to promote mental health and protection against harms (e.g. addiction, suicide, and delinquency). Life skill training influences common underlying factors in many areas of mental health promotion and harm reduction. Its characteristics have broadened the educational domain and underpinned informative approaches to life. Although knowledge and application of life skills in mental health promotion and primary prevention programs are different from social impairments, life skills play an important role in all of these domains. Therefore, life skill training is a comprehensive program designed to teach both personal and social skills, with great potentials for preventing different social problems and injuries.

\section{Empowerment of individuals}

A life skill training program is a holistic approach for the empowerment of individuals to understand themselves, others, and the environment. Skill training is not only a type of learning but also a form of knowledge and information acquisition. Training also influences an individual's skills, attitudes, and values. Besides learning to apply life skills in real-life situations, individuals can also learn about different situations.

\section{Realization of potentials and adapting to life changes}

Life skill training programs transform knowledge and attitude into actual abilities and prepare the individual for changing life conditions, such as urbanization and family 
structure changes. Also, cultural changes help people cope with everyday situations in ways that they are constructive for the family and society [11]. Maligen, a life skill trainer, believes that life skill training is not a therapy, but a goal-based practice; accordingly, we try to think about solutions instead of addressing the causes of problems. In other words, this approach teaches life skills by providing new and effective solutions to problems and ultimately helps the individual to be his/her own life coach [12].

The purpose of this study was to highlight the importance of life skill training and establish a questionnaire to assess its quality. We attempted to develop a questionnaire based on published articles and policies, developed by the United Nations Office on Addiction and Crime in 2008 [13], which identified four main life skills as the most important preventive factors for addiction. Effectiveness of life skill training interventions can be assessed among adolescents above 10 years. It should be noted that this questionnaire was not available in Iran, and the researchers decided to compile and simplify other scales into a short questionnaire, which was comprehensible to adolescents [13].

\section{Methods}

This study was descriptive and correlational in terms of data collection and developmental in terms of its purpose. After reviewing previous studies and the designed questionnaire, the basic form of the adolescent life skill questionnaire was designed with four subscales: problemsolving abilities (10 articles), self-control ability (11 articles), decision-making (9 articles), and ability to say "no" (11 articles). It was rated on a five-point Likert scale ( $1=$ he/she is so similar to me; $5=$ he/she is not similar to me at all). The questionnaire was designed for the general population. Therefore, some of its items needed to be revised for the adolescent population. In the next step, the reliability and content validity of the questionnaire were assessed regarding the domains of knowledge and attitude.

The formal validity of the questionnaire was reviewed by 12 psychologists in terms of the validity, intelligibility of the items as well as its psychological aspects. The items of the questionnaire were evaluated regarding three main characteristics of 1 . Intelligibility; 2. Fluency of sentences; and 3. Adolescents' ability to answer the questions and the basic concepts did not change. After summarizing and reviewing the meeting with 12 psychologists, the following changes were made in the articles $(5,32,36,6,11,23,29)$ :
1. The tense of all sentences was changed from past to present.

2. In item 5, the word "avoid" was replaced with the word "becoming far".

3. In item 11, the word "must" was replaced with "I wish".

4. In item 23, the word "usually" was replaced with the word "always".

5. In item 29, the word "always" was deleted.

6. In item 32, the phrase "it can" was replaced with the word "sure".

7. In item 36, "I don't know the solution" was replaced with "the problems I have".

In the next step, the content validity was quantitatively assessed by measuring the Content Validity Ratio (CVR) and Content Validity Index (CVI). To determine CVR, the experts were required to rank each item on a three-point scale of "necessary", "useful but not necessary", and "not necessary". Twelve experts were then asked to review the select the items, which were then modified regarding the wording of phrases and sentences to analyze CVI and CVR.

Data, including age, gender, and educational status, were presented with a predetermined design in three stages among 120 adolescents (females and males), who were selected from District 15 of Tehran, Iran. Before administering the questionnaire, explanations were given to the participants on how to complete the questionnaire, and they were informed about the importance of the study, the integrity of responses, the confidentiality of information, and the anonymity of the questionnaire. Questionnaires were distributed among students in three stages of pre-test, post-test, and a follow-up. Data were then analyzed using correlation tests, independent tests, regression analysis, and exploratory factor analysis. Based on the factor analysis, 40 items were developed from a combination of four scales (self-control, problem-solving skills, decision-making skills, and assertiveness) and loaded on four factors:

Factor one: Laziness, problems, and self-control skills;

Factor two: Assertiveness and ability to say "no";

Factor three: Problem-solving skills; and

Factor four: Decision-making skills. 


\section{Findings}

According to Table 1, CVR should be greater than 0.56 . CVR of all items exceeded 0.56 , and the content validity of all items was confirmed. Also, the average CVI must be 0.79. In this study, the average CVI was 0.89 ; therefore, the content validity of all items was confirmed. Finally, a 40-item researcher-made questionnaire was developed, measuring decision-making skills, problem-solving skills, self-control skills, and adolescents' life skills.

\section{Exploratory factor analysis via Varimax rotation}

This method is the most common internal consistency reliability test used in most studies, which represents the proportion of a group of items measuring consistency. While a Cronbach's alpha of $\geq 0.7$ is generally acceptable for a question to remain on a scale, many researchers find a Cronbach's alpha of 0.8 to be acceptable. Overall, a Cronbach's alpha of 0.7 indicates a $70 \%$ consistency of the scores in a tool.

In this study, 120 adolescents (males and females) were selected from District 15 of Tehran, Iran. The questionnaire was distributed in three stages of pre-test, post-test, and follow-up at certain intervals between adolescents. Exploratory factor analysis was performed via Varimax rotation. Based on the factor analysis, 40 items of the questionnaire, including four scales, had suitable factor loadings, and no item was removed. Table 2 presents the results of the factor analysis. The reliability of the questionnaire was estimated at 0.98 , based on Cronbach's alpha. The criterion validity of the questionnaire was estimated at 0.67 with concurrent implementation of the Adolescent Psychopathology Scale (APS) scale, which was within the acceptable range. As mentioned earlier, the factors included in the questionnaire were as follows:

Factor one: Laziness and self-control skills;

Factor two: Assertiveness and ability to say "no";

Factor three: Problem-solving skills; and

Factor four: Decision-making skills.

\section{Discussion}

The questionnaires on self-control, problem-solving, decision-making, and assertiveness were originally designed for the adult population. Therefore, the developed questionnaire was not intended for the adolescent population and needed to be revised. For this purpose, several statistical methods were utilized. First, the content validity and face validity of the questionnaire were examined by 12 experts (Table 3 ) in the field of addiction, without removing any item, only with minor modifications. The content validity of the questionnaire was found to be moderately high.

Forty items of the questionnaire, which were extracted from four scales of self-control, problem-solving, decision-making, and assertiveness, were found to be well loaded (Table 1). The reliability of the questionnaire was evaluated among five individuals, indicating its accept-

Table 1. Content Validity Ratio (CVR) and Content Validity Index (CVI) of the questionnaire

\begin{tabular}{|c|c|c|c|}
\hline Questions & CVR & CVI & Accept or Reject \\
\hline 1 & 0.66 & 0.83 & Accept \\
\hline 2 & 0.83 & 0.92 & Accept \\
\hline 3 & 0.83 & 0.83 & Accept \\
\hline 4 & 1.00 & 1.00 & Accept \\
\hline 5 & 1.00 & 0.83 & Accept \\
\hline 6 & 0.66 & 0.83 & Accept \\
\hline 7 & 0.83 & 1.00 & Accept \\
\hline 8 & 0.83 & 0.83 & Accept \\
\hline 9 & 1.00 & 0.83 & Accept \\
\hline 10 & 1.00 & 0.92 & Accept \\
\hline
\end{tabular}




\begin{tabular}{|c|c|c|c|}
\hline Questions & CVR & CVI & Accept or Reject \\
\hline 11 & 0.66 & 0.83 & Accept \\
\hline 12 & 0.83 & 1.00 & Accept \\
\hline 13 & 0.66 & 0.83 & Accept \\
\hline 14 & 0.66 & 0.83 & Accept \\
\hline 15 & 1.00 & 0.92 & Accept \\
\hline 16 & 1.00 & 1.00 & Accept \\
\hline 17 & 0.66 & 0.83 & Accept \\
\hline 18 & 0.83 & 0.92 & Accept \\
\hline 19 & 0.66 & 0.83 & Accept \\
\hline 20 & 0.83 & 1.00 & Accept \\
\hline 21 & 0.83 & 0.83 & Accept \\
\hline 22 & 0.83 & 0.92 & Accept \\
\hline 23 & 0.66 & 0.83 & Accept \\
\hline 24 & 0.66 & 1.00 & Accept \\
\hline 25 & 1.00 & 0.83 & Accept \\
\hline 26 & 0.83 & 1.00 & Accept \\
\hline 27 & 0.83 & 0.92 & Accept \\
\hline 28 & 1.00 & 1.00 & Accept \\
\hline 29 & 0.66 & 0.83 & Accept \\
\hline 30 & 0.66 & 0.83 & Accept \\
\hline 31 & 0.83 & 1.00 & Accept \\
\hline 32 & 0.66 & 0.83 & Accept \\
\hline 33 & 0.83 & 0.92 & Accept \\
\hline 34 & 0.83 & 1.00 & Accept \\
\hline 35 & 1.00 & 0.92 & Accept \\
\hline 36 & 0.66 & 0.83 & Accept \\
\hline 37 & 0.83 & 1.00 & Accept \\
\hline 38 & 1.00 & 0.92 & Accept \\
\hline 39 & 0.83 & 0.83 & Accept \\
\hline 40 & 0.66 & 0.83 & Accept \\
\hline
\end{tabular}


Table 2. Reliability of life skill questionnaire and its factors based on Cronbach's alpha

\begin{tabular}{ccccc}
\hline Reliability & Factor $\mathbf{1}$ & Factor $\mathbf{2}$ & Factor 3 & Factor 4 \\
\hline Cronbach's alpha & 0.71 & 0.85 & 0.76 & 0.81 \\
Guttman's scale & 0.84 & 0.79 & 0.77 & 0.62 \\
\hline
\end{tabular}

Table 3. Number of the experts and Content Validity Ratio (CVR)

\begin{tabular}{cccc}
\hline Number of Experts & CVR & Number of Experts & CVR \\
\hline 5 & 0.99 & 11 & 0.59 \\
6 & 0.99 & 12 & 0.56 \\
7 & 0.99 & 13 & 0.54 \\
8 & 0.75 & 14 & 0.51 \\
9 & 0.78 & 15 & 0.49 \\
10 & 0.62 & 20 & 0.42 \\
\hline
\end{tabular}

Iranian Rehabilitation Dourna

able factor loading. Finally, the statistical norm of the questionnaire was presented to an adolescent population (age $>10$ years) in Tehran, Iran. Overall, the designed questionnaire has several characteristics: 1 . Specific design for the adolescent population; 2 . Specific functional structure; 3. Applicability for study of adolescents of any gender; 4. Suitability for the Iranian population; and 5. Applicability in educational, research, and clinical fields.

\section{Ethical Considerations}

Compliance with ethical guidelines

All ethical principles are considered in this article.

\section{Funding}

This article was extracted from the $\mathrm{PhD}$. thesis of Hossein Gharaati Sotoudeh at the Department of Psychology, Islamic Azad University, Rudehen, Iran.

\section{Authors' contributions}

All authors contributed in preparing this article.

\section{Conflict of interest}

The authors declared no conflict of interest.

\section{Acknowledgments}

We would like to thank Dr. Omran Mohammad Razzaghi, Associate Professor of Tehran University of Medical Sciences, and Dr. Maral Mardaneh for their cooperation.

\section{References}

[1] United Nations Office on Drugs and Crime. Executive summary conclusions and policy implications [Internet]. 2018 [Updated: 2018 Jun]. Availeble from: https://www.unodc. org/wdr2018/prelaunch/WDR18_Booklet_1_EXSUM.pdf

[2] Rahimi-movaghar A, Aminesmaili M, Sharifi V, Hefazi M, Motevallian A, Hajabi A, et al. [National survey of mental health 2010-2011 (Persian)]. Tehran: Mehrsa; 2014. https:// b2n.ir/918297

[3] United Nations Office on Drugs and Crime. International Standards on the Prevention of Drug Abuse [Iran's Drug Control Headquarters, Persian trans)] [Internet]. 2013 [Updated 2020 Sep 29]. Available from: https://www.unodc. org/documents/islamicrepublicofiran/int-standard-fa.pdf

[4] Barati Sedeh F. [There are 135000 addicted women in country (Persian)]. [Internet]. 2014 [Updated 2014 Dec 09]. Available from: www.irna.ir/news/81420471/

[5] Serami H. [The average age of onset of substance use in adolescents is 15 years (Persian)] [Internet]. 2019 [Updated 2019 Feb 25]. Available from: www.irna.ir/news/83221425/

[6] Palmer RH, Young SE, Hopfer CI, Corley RP, Stallings MC, Crowley TJ, et al. Developmental epidemiology of drug use and abuse in adolescence and young adulthood: Evidence of gener- 
alized risk. Drug and Alcohol Dependence. 2009; 102(1-3):78-87. [DOI:10.1016/j.drugalcdep.2009.01.012] [PMID] [PMCID]

[7] Young KS. The research and controversy surrounding internet addiction. CyberPsychology \& Behavior. 1999; 2(5):381-3. [DOI:10.1089/cpb.1999.2.381] [PMID]

[8] Gazda GM, Childers WC, Brooks DK. Foundations of counseling and human services. New York: McGraw-Hill; 1987.

[9] Shimamoto K, Ishii M. Ginter EJ. [Development of a daily life skills scale for college students (Japanese)]. The Japanese Journal of Educational Psychology. 2006; 54(2):211-21. [DOI:10.5926/jjep1953.54.2_211]

[10] Taremian F, Mehryar AH. Effectiveness of "Life Skills Training Program" in Prevention of Drug Use Among Secondary School Students. Quarterly Journal od Zanjan Medical Sciences and Health Services. 2009; 16(65):77-88.

[11] Radfar S, Hamidi F. Life skills training. Tehran: Publication of Institute of Engineering and Sciences of Veterans; 2006.

[12] Maligin A. Life teaching: Change your life in seven days. P. H. Farhangi Persian trans]. Tehran: Nashre Sales; 2002.

[13] Drug addiction treatment: A community-based Iran: UN Office on addiction and crime; 2008. Available from: https:// www.unodc.org/documents/islamicrepublicofiran/publications/pub-cummiunitybased-FA.pdf 